\title{
DESNUTRIÇÃO RECENTE, CRÔNICA E PREGRESSA EM QUATRO LOCALIDADES DO ESTADO DE PERNAMBUCO, BRASIL
}

\author{
Elenice Costa * \\ Sylvia de Azevedo Mello Romani* \\ Malaquias Batista Filho: \\ Ana Neire da Rocha**
}

\begin{abstract}
COSTA, E. et al. Desnutrição recente, crônica e pregressa em quatro localidades do Estado de Pernambuco, Brasil. Rev. Saúde públ., S. Paulo, 15:211-20, 1981.

RESUMO: Foram estudadas 1.712 crianças menores de 6 anos, residentes nas cidades de Recife (Zona Litorânea), Ferreiros (Zona da Mata), Brejo da Madre de Deus (Zona do Agreste) e Afogados da Ingazeira (Zona do Sertão) - Estado de Pernambuco (Brasil) - com o propósito de comparar a prevalência da desnutrição protéico-energética (DPE) nas quatro localidades $e$ contribuir para o mapeamento nosográfico da desnutrição do Estado. A situação nutricional das crianças foi determinada através dos critérios de Gomez, Ariza-Macias e Seoane-Lathan modificado. A relação peso/altura não discrimina muito bem a situação de três das comunidades estudadas. Segundo o critério de Seoane-Lathan modificado, são comprovadas diferenças significativas na prevalência de desnutrição dos três tipos (recente, crônica e pregressa) entre o Recife e as cidades do interior, com exceção da situação na Zona do Agreste (Brejo da Madre de Deus).
\end{abstract}

UNITERMOS: Desnutrição, Pernambuco, Brasil. Desnutrição protéico - calórica.

\section{TNTRODUÇAO}

A caracterização do estado nutricional da população, sob o ponto de vista qualitativo e quantitativo, representa, atualmente, um dos objetivos centrais dos estudos sobre distribuição do processo saúde-doença, não apenas no campo epidemiológico convencional como, sobretudo, na esfera administrativa.

Dois aspectos, mutuamente complementares, aparecem com relevante interesse nos estudos de campo, no caso específico da desnutrição energético-protéica (DEP).
O primeiro, refere-se à necessidade programática de estabelecer a distribuição cartográfica do programa, de modo a situar, especialmeite, as áreas de maior ou menor risco e alocar recursos em função da magnitude da DEP. O segundo aspecto centra-se no caráter ainda experimental dos indicadores utilizados na descrição do quadro carencial a nível de populações.

No que se aplica à cartografia da DEP, o grupo de nutrição humana do Departamento de Nutrição do Centro de Ciências

* Do Departamento de Nutrição do Centro de Ciências da Saúde da Universidade Federal de Pernambuco - Cidade Universitária - 50000 - Recife, PE - Brasil.

** Do Serviço Soctal do Comércio - Rlia 13 de Maio, 455 - Santo Amaro - 50000 - Recife, $\mathrm{PE}$ - Brasil. 
COSTA, E. et al. Desnutrição recente, crônica e pregressa em quatro localidades do Estado de Pernambuco, Brasil. Rer. Saúde pübl., S. Paulo, 15:211-20, 1981.

da Saude da UFPE consideruu a conveniência de estudar, através de metodologia padronizada, amostras populacionais de 3 niveis. O primeiro, utilizou dados de capitais brasileiras de áreas distintas. São Luís, no centro-norte, Recife, no nordeste, e São Paulo, no sul ${ }^{3}$. O critério para a escolha das 3 capitais foi basicamente operacional, acreditando-se, em base de várias evidências, que tais centros respondem bem às características das regiōes em que se acham situados. O segundo nivel de informaçōes, tratado no presente trabalho, refere-se ao Estado de Pernambuco, ocupando-se de 4 populações urbanas de distintas regiōes fisiográficas dessa unidade federativa. Finalmente, o terceiro nivel estuda, comparativamente, áreas urbanas e localidades rurais do Estado de Pernambuco *. É, portanto, um critério baseado em relações comparativas em escala de macro, meso e microespaços geográficos.

Uma das finalidades deste trabalho é contribuir para o estudo dos indicadores da DEP. Na realidade, a quase totalidade das pesquisas de campo tem se limitado a determinar a frequência e graus da desniltrição, ou a rotular, nos casos mais adiantados, suas formas extremas: marasmo e "kwashiorkor". É um instrumental metodológico que, emhora útil, deixa ainda muito a desejar.

Algumas tentativas têm sido efetuadas, visando superar esse inconveniente. Mora-Parra e col.s e, mais recentemente, Seoane e Lathan 10, propuseram critérios relativamente simples de classificação do estado nutricional, considerando as variáveis idade, peso e altura. Batista Filho: em 1976, sugeriu e testou nova sistematização do método de Seoane-Lathan, de modo a universalizar sua aplicação, o que não ocorria com a proposta original. Com as classificaçōes de Mora-Parra e Seoane-Lathan, torna-se possivel avaliar efeitos recentes $e$ tardios da DEP, sobre indivíduos e populações. A descrição do problema torna-se muito mais consistente e ilustrativa. Vantajosamente pode-se enquadrar a normalidade somatométrica e caracterizar a desnutrição em suas diversas fases, ou seja, como processo recente, como seqüela ou como processo crônico, supondo efeitos tardios e patogenia atual.

No presente trabalho, pretende-se aprofundar a aplicação prática do método de Seoane-Latham modificado 2 , no estudo do estado nutricional de crianças de Recife, Ferreiros, Brejo da Madre de Deus e Afogados da Ingazeira. As \& cidades localizam-se em distintos quadros sócio-econômicos do Estado de Pernambuco, superpondo-se a áreas fisiográficas bem diversificadas.

É muito possivel, por hipótese, que estas condiçōes do macro-ambiente resultem em modelos próprios da DEP, seja no que se refere à magnitude do problema, seja ainda no aspecto de suas manifestações especificas. Parece, portanto, $11 \mathrm{~m}$ bom campo para novos testes do método proposto.

Especificamente, os objetivos deste trabaIho são:

- Estudar comparativamente, a prevalência da DEP em + localidades do Estado de Pernambuco, representando distintas áreas fisiográficas e condições sócin-econômicas.

- Contribuir para o desenvolvimento de métodos mais adequados à caracterização epidemiológica da DEP.

\section{MATERIAL E METODOS}

Foram estudadas 1.712 crianças de 0-60 meses, sendo 1.169 do Recife (Zona Litorânea) 3.6. 260 de Ferreiros (Zona da Mata). 207 de Brejo da Madre de Deus (Zona do Agreste) e 76 de Afogados da Ingazeira (Zona do Sertão).

No caso do Recife considerou-se apenas o espaço urbano não metropolitano, escolhendo-se ruas ao azar (10 estágio) e domicilios por sorteio ( $2^{\circ}$ estágio). Nos demais núcleos urbanos, os domicilios foram selecionados por sorteio, a partir da planta cadastral das cidades, elaborada pelas prefeituras. 
COSTA, E. et al. Desnutrição recente, crônica e pregressa em quatro localídades do Estado de Pernambuco, Brasil. Rev. Saúde públ., S. Paulo, 15:211-20, 1981.

Com exceção do caso de Afogados da Ingazeira, onde não foi cumprido o plano de estudo por falta de recursos financeiros, os espaços amostrais foram definidos adotando-se o intervalo de confiança de $95 \%$ e grau de fidedignidade de $\pm 5 \%$, para o universo de crianças com menos de 5 anos.

\section{Métodos}

$O$ estado de nutrição das crianças foi determinado através dos critérios de Gomez ${ }^{5}$, Ariza-Macias ${ }^{1}$ e Seoane-Lathan modificado 2 , tomando-se como padrão de normalidade somatométrica a tabela de Santo André IV T

Foi adotado, como chave de classificação, - seguinte gabarito, na classificação de Seoane-Lathan :

\section{Classificação Adequação Adequação Alt/Idade Peso/altura}
A. Normalidade ou eutrofia
$\geqslant 92 \% \geqslant 90 \%$
B. Desnutrição recente
C. Desnutrição pregressa

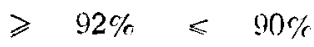
Desnutrição crônica$$
<92 \%>90 \%
$$$$
<92 \% \approx 90 \%
$$

No tratamento estatístico dos resultados foi utilizado o teste das proporções (erro da diferença de percentuais).

O material informativo necessário está representado pelos fichários de casos catalogados pelo Departamento de Nutrição supramencionado, no período de 1974 a 1975.

\section{RESULTADOS}

\section{Classificação de Gomez}

De acordo com a classificação de Gomez ", que utiliza a relação peso/idade, $47,3 \%$ das crianças examinadas na cidade do Recife apresentaram-se desnutridas, sendo $11,4 \%$ enquadradas nas condições de Il e III graus. Em Ferreiros, a desnutrição ocorre em $71,5 \%$ das crianças estudadas, com 26,9\% nas formas de II e III graus. Com relação à cidade de Brejo da Madre de Deus, a desnutrição acomete $60,4 \%$ das crianças, estando $11,6 \%$ com desnutrição de Il e III graus. En Afogados da Ingazeira, em $61,8 \%$ de crianças desnutridas, $23,3 \%$ se incluem nas formas de II e III graus.

Segundo o critério de Gomez (peso/ idade), todas as comunidades do interior apresentaram uma prevalência de desnutrição superior ao Recife, estatisticamente significativa ao nível de $1 \%$. No caso de Afogados da Ingazeira, a hipótese nula é recusada ao nível de $5 \%$. (Tabelas 1 e 4 ).

\section{Classificação de Ariza-Macias}

Utilizando-se a relação peso/altura, dentro do critério proposto por Ariza-Macias ${ }^{1}$. verifica-se que, no Recife, $16,7 \%$ das crianças apresentam desnutrição, com $1,7 \%$ dos casos na forma $d_{2}$. Em Ferreiros, a preva. lência da desnutrição, segundo este critério, foi de $24,6 \%$, incluindo $6,9 \%$ nas formas moderada $\left(d_{2}\right)$ e grave $\left(d_{3}\right)$. Em Brejo cla Madre de Deus, $21,7 \%$ da amostra estudada apresentava desnutrição, sendo $3,3 \%$ dos casos de $d_{2}$ e $d_{3}$. Em Afogados da Ingazeira assinala-se $18,4 \%$ de desnutridos, dos quais, $6,6 \%$ são portadores da forma $\mathrm{d}_{2}$. Apenas em Ferreiros e em Brejo da Madre de Deus foram encontrados casos de $\mathrm{d}_{3}$.

Segundo esse critério de classificação, apenas Ferreiros se distingue significativamente da cidade do Recife. (Tabelas 2 e 4).

\section{Classificaşāo de Seoane-Lathan modificada}

Segundo a classificação de Seoane-Lathan modificada 2 , foi possível estabelecer a seguinte distribuição do estado nutricional, 
COSTA, E. et Hl. Desnutrição recente. crônica e pregressa em quatro localidades do Estado de Pernambuco, Brasil. Rev. Saúde púb7., S. Paulo, 15:211-20, 1981.

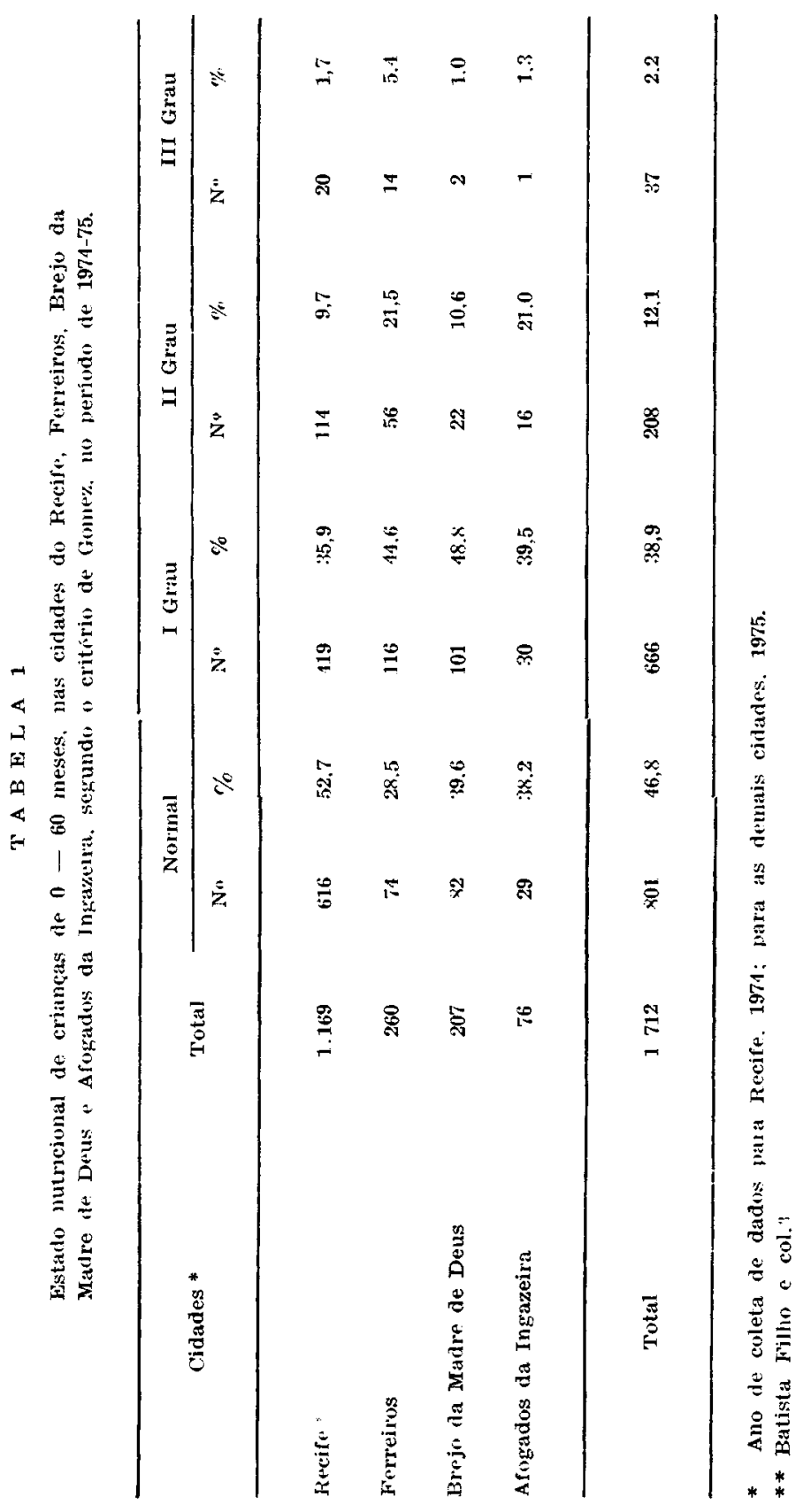


COSTA, E. et al. Desnutrição recente, crônica e pregressa em quatro localidades do Estado do Pernambuco, Brasil. Rev. Saude públ., S. Paulo, 15:211-20, 1981.

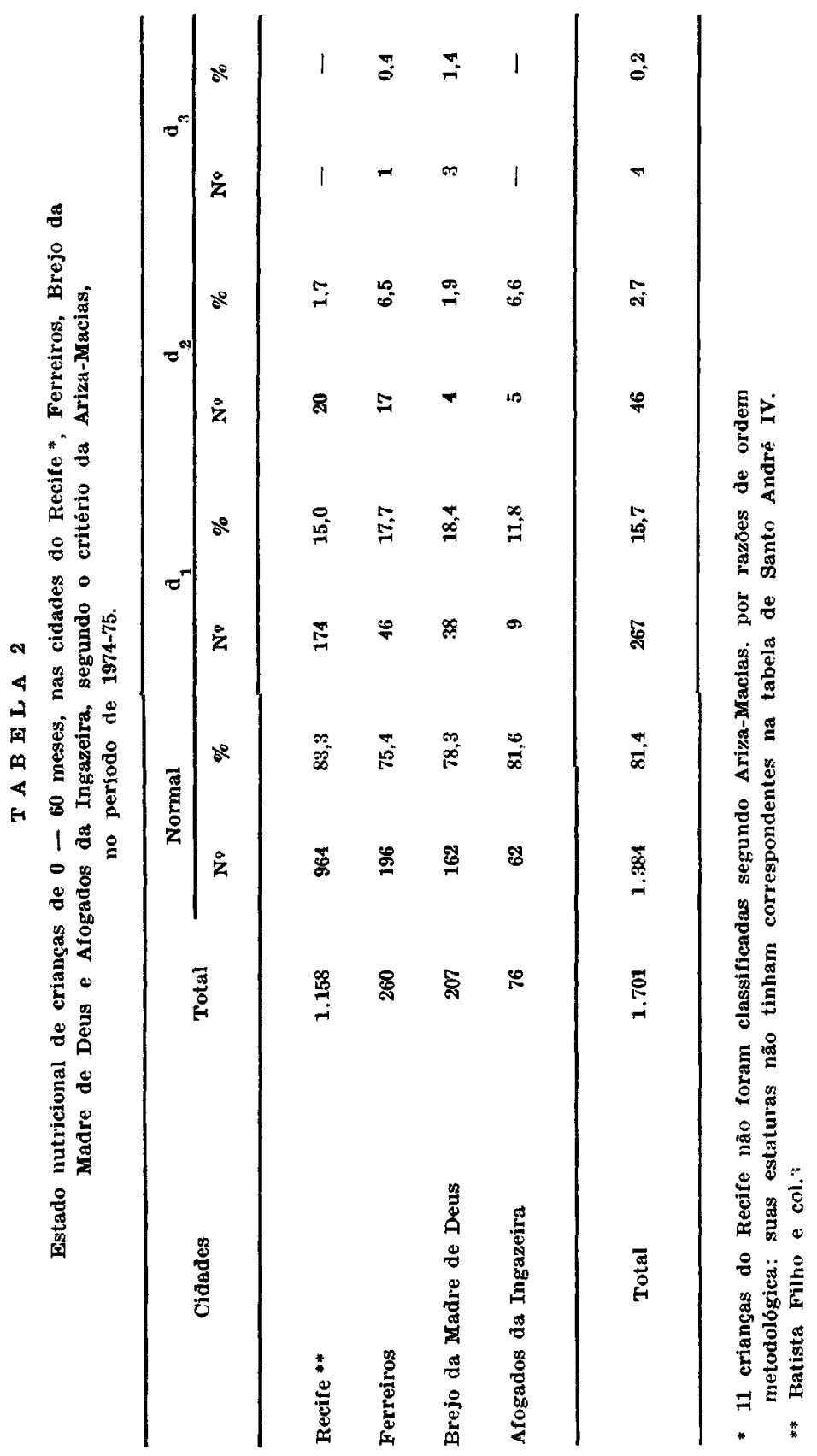


COSTA, E. et al. Desnutrição recente, crônica e pregressa em quatro localidades do Estado do Pernambuco, Brasil. Rev. Saúde públ., S. Paulo, 15:211-20, 1981.

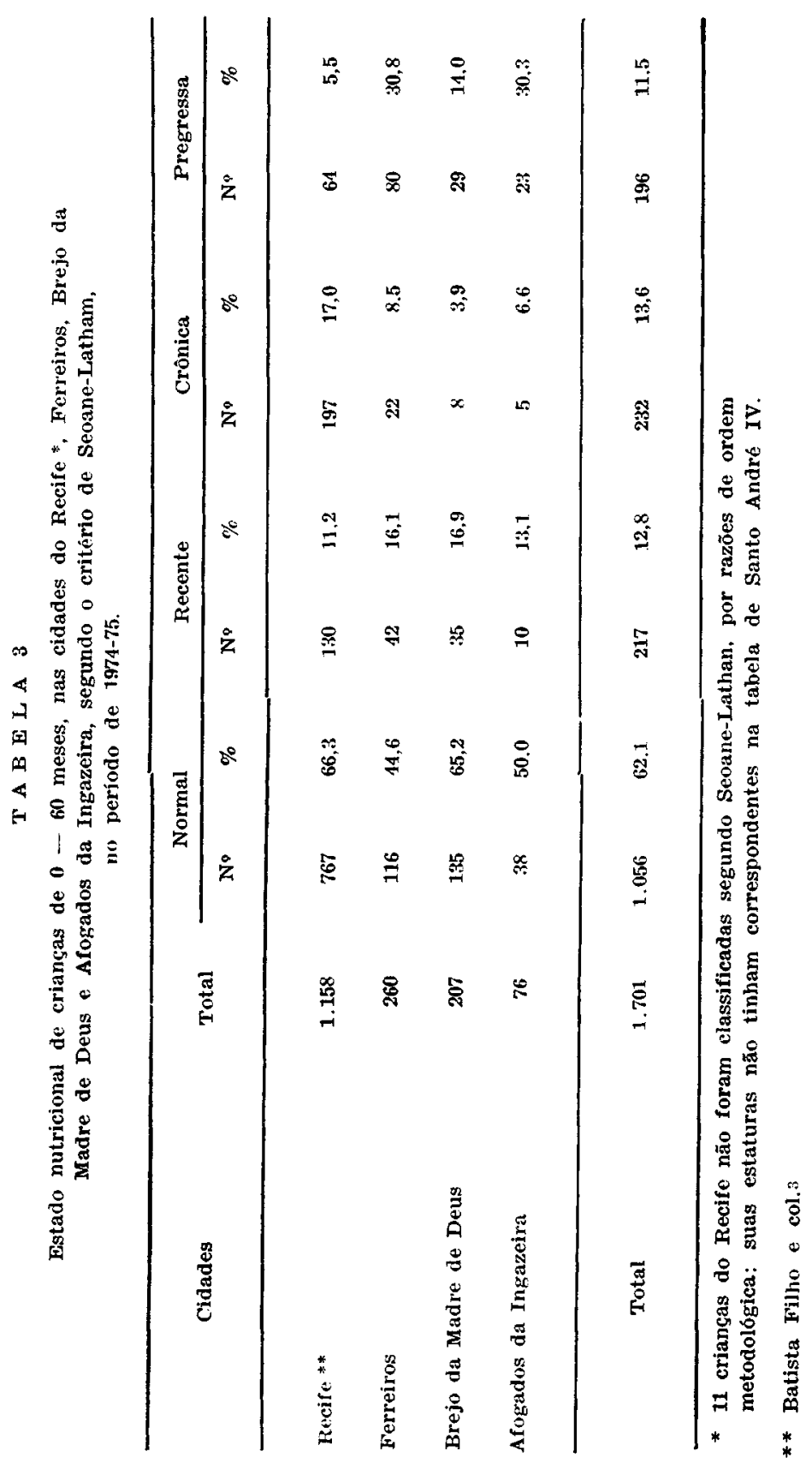




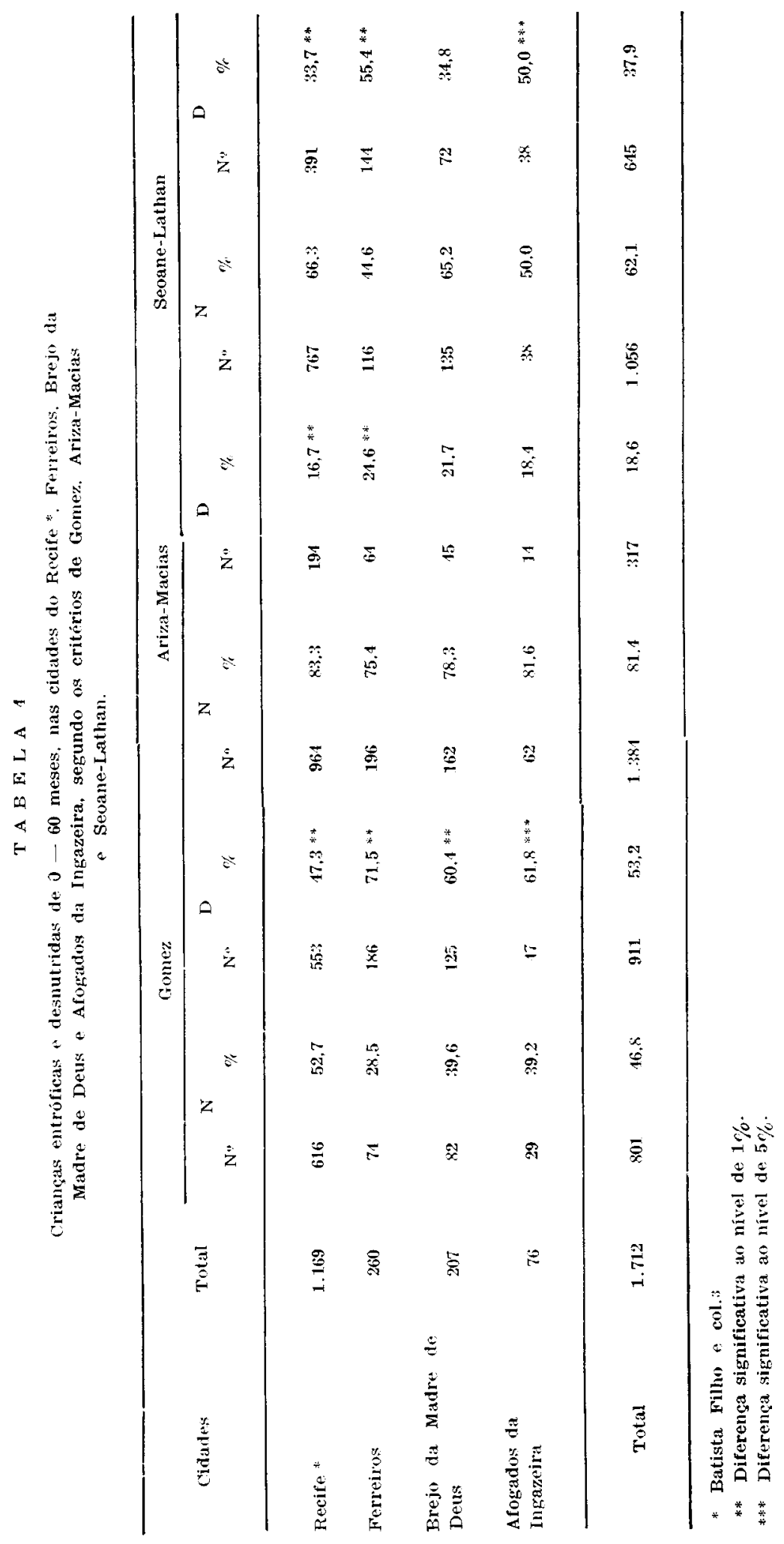


COSTA, E. et al. Desnutriçăo recente, crónica e pregressa em quatro localidades do Estado de Pernambuco, Brasil. Rev. Stude pübl., S. Paulo, 15:211-20, 1981.

derivada dos parâmetros de altura/idade e peso/altura: em Recife, $66,3 \%$ das crianças são eutróficas, $33,7 \%$ são desnutridas, sendo que $11,2 \%$ apresentan desnutriçāo atual, $17 \%$ são portadoras de desnutrição crônica e, em $5,5 \%$, prevalece o quadro de desnutrição pregressa. Em Ferreiros, o percentual de desnutridos $(\mathbf{5 5 , 4} \%)$ supera o de crianças en estado nutricional normal $(44,6 \%)$, contribuindo, para isto, o elevado percentual de desnutrição pregressa, $30,8 \%$. Em Brejo da Madre de Deus, a situação é semelhante à da cidade do Recife, apresentando um percentual de $65,2 \%$ de crianças eutróficas e $34,8 \%$ de crianças desnutridas, sendo $16,9 \%$ de desnutrição recente, $3,9 \%$ de desnutrição crônica e $14,0 \%$ de desnutrição pregressa. Em Afogados da Ingazeira, metade da amostra estudada apresentava desnutrição, com a prevalência de $13,1 \%$ de desnutrição recente, $6,6 \%$ de desnutrição crônica e $30,3 \%$ de desnutriçăo pregressa (Tabelas 3 e 4 ).

Segundo esse critério, foram comprovadas diferenças significativas na prevalència da desnutrição entre Recife e as cidades do interior, con exceção de Brejo da Madre die Deus.

\section{COMENTÁRIOS E CONCLUSOES}

A utlização simultânea de três métodos de avaliação antropométrica do estado nutricional em quatro diferentes comunidades urbanas de Pernambuco possibilita algumas consideraçōes sobre o perfil epidemiológico da desnutrição energético-protéica no Estado, bem como aprofundar a experiência metodológica relacionada com a aplicação dos critérios de avaliação aqui adotados.

Assim, parece bem definida a conclusão de que o atraso físico de crescimento é mais freqüente nas cidades interioranas que em Recife. A prevalência de desnutrição segundo o critério de Gomez " mostra que o afastamento ponderal das crianças em relação ao canal normal de crescmiento para a idade é estatisticamente significativo nas cidades de Ferreiros (Zona da Mata), Brejo da Madre de Deus (Zona do Agreste) e Afogados da Ingazeira (Zona do Sertão), em relação ao Recife (Litoral). No entanto, as três primeiras cidades apresentam, nos limites da amostra examinada, uma situação homogênea entre si. Há a considerar, entretanto, a baixa representatividade de Afogados da Ingazeira, em função do tamanho reduzido da amostra.

Infelizmente, ainda por conta do pequeno espaço amostral, fica invalidada a hipótese de um estudo comparativo da frequêencia das diferentes formas de desnutrição (I, Il e III graus). Dai a opção pela análise estatística da prevalência acumulada da DEP.

Já em relação à classificação peso/altura (método de Ariza-Macias), apenas Ferreiros difere significativamente da cidade do Recife, não se verificando diferenças estatisticamente significativas com relação às outras cidades estudadas. A prevalência acumulada das diferentes formas de desnutrição é semelhante em três das comunidades analisadas. Conclusivamente, parece evidente que a ordem de grandeza e a natureza das nuanifestações da DEP diferem do Recife para as cidades do interior, sendo relativamente homogêneas entre estas.

Esta discrepância entre a frequiência de casos de desnutrição, obtida através das classificações de Gomez " e Ariza-Macias ' contribui, mais uma vez, para consolidar as recentes reinterpretações dos indicadores antropométricos do estado nutricional :.9. $\mathrm{Na}$ verdade, a classificação de Gomez funciona como um bom indicador epidemiológico, podendo discriminar situaçōes ecológicas que, pelo próprio senso comum, são evidentemente distintas. Tal poder de discriminação, no entanto, não existe em relação ao método de Ariza-Macias mais aplicável às avaliações de nível individual, como aferidor da fase patogênica da desnutrição energético-protéica. 
COSTA, E. et al. Desnutriçăo recente, crônica e pregressa em quatro localidades do Estado de Pernambuco, Brasil. Rev. Saúde públ., S. Paulo, 15:211-20, 1981.

E possivel mesmo estabelecer algumas especulações sobre a fisiopatologia da desnutrição, a partir do confronto desses resultados. Há situaçōes em que o potencial genético de crescimento, contrariado por condições ambientais (fundamentalmente pelos agravos nutricionais), deixa de ser claramente cumprido (e isto torna-se evidente nos dados da classificação de ciomez, a nivel populacional). No entanto, em escala individual, mecanismos eficazes de ajuste biológico trabalham no sentido de restaurar a desaceleração do crescimento, ninimizando, assim, os efeitos da própria desnutrição. Este dualismo de respostas possibilita a detecção de contrastes marcantes da distribuição de quadros de desnutrição em relação a um método de des(rição (Gomez), enquanto um outro critério (Ariza-Macias) revela uma situação mais homogênea. Parece, portanto, superada a busca de un critério de classificação que possa conciliar os dois parâmetros (peso/ idade e peso/altura), no sentido de aproximar os resultados respectivos. São, de fato, parâmetros bem distintos de um mesmo problema.
A classificação de Seoane-Latham modificada *, como método isolado, reúne a vantagem de valer como um indicador epidemiológico e clínico da desnutrição. Neste caso, os testes estatísticos comprovan diferenças significativas na prevalência dos casos acumulados de desnutrição (recente, crônica e pregressa) entre Recife e as cidades do interior, com exceçăo de Brejo da Madre de Deus.

É fato que esta classificação, embora conciliando informaçóes de interesse epidemiológico e clínico, perde um pouco de acuidade em relação a alguns aspectos que podem interessar ao administrador ou ao encarregado da prestação direta de serviços de saúde a nível individual. Por exemplo, não se sabe qual a intensidade do agravo nutricional, em cada forma de desnutrição. Por outra parte, a prevalência de desnutrição não apresenta a escala de frequiencia que aparece na classificação de Gomez $e$ isto seria um indicativo de que a sensibilidade do parâmetro, sob o ponto de vista epidemiológico, tica reduzida.

COSTA, E. et al, [Malnutrition - recent, chronic, and past - in four localities in Pernambuco, Brazil]. Rev. Saúde públ., S. Paulo, 15:211-20, 1981.

ABSTRACT: In order to compare the prevalence of PCM in four localities and to contribute to the nosographic mapping of malnutrition in the State of Pernambuco (Brazil) the nutritional intake of about 1,712 children under 6 years of age, living in Recife (ccastal area), Ferreiros (forest area), Brejo da Madre de Deus (arid area), and Afogados da Ingazeira (scrubland), was classified; for this the following methods were used: the Gomez, the Ariza-Macias, and the Secane-Lathan (modified). According to the Gomez classification and from a statistical point of view, the prevalence of malnutrition was higher in the countryside than in Recife. The weight/height ratio does not clearly show the situation in three of the communities under study. Moreover, the mcdified Seoane-Lathan method revealed no significant difference in the three types of malnutrition (recent, chronic, and past) between Recife and the other cities, with the exception of Brejo da Madre de Deus.

UNITERMS: Nutrition disorders, Pernambuco, Brazil. Protein-calorie malnutrition. 
COSTA. E. et al. Desnutrição recente. crỏnica e pregressa om quatro localidades do Estado de Pernambuco. Brasil. Rer. Saúde pübl, S. Paulo, 15:211-20, 1981.

\section{REFERENCIAS BIBLIOGRAFICAS}

1. ARIZA-MACIAS, J. Metodo para la evaluación del crecimiento de hombres $y$ mujeres desde el nacimiento hasta los 20 años, para uso del nivel nacional $y$ internacional. Arch. Intinoumer. Nutr.. $22: 531-46.1972$.

2. BATISTA FILHO, M. Prevaléncia cestáyzos da desnutriçâo protéico-calórica em crianças da cidade de São Paulo (Brasil). São Paulo, 1976. [Tese de doutoramento - Faculdade de Saúde Pública da USP]

3. BAtista FIlHo, M. et al. Desnutriçâo protéico-energética em 3 capitais brasileiras: São Luís, Recife e São Paulo. Bol. Ofic. sanit. panamer., 90:48-58, 1981

4. BATISTA FILHO, M. et al. Estado nutricínal de pré-escolares de comunidades rurais do Nordeste brasileiro. In: Congresso Internacional de Nutrição, $11^{4}$, Rio de Janeiro, 1978. Resumos. Rio de Janeiro. 1978. p. 182

5. GOMEZ, F. Desnutrición. Bol. Med. Hospy. inf., México, 3:543-51, 1946.

6. LUCENA. M. A. F. de Estudo antropométrico comparativo de crianças de 1 a 60 meses, em duas cidades do Nordeste brasileiro: Recife ( $P E$ ) e Sdo Luís (MA).
Recife, 1975. IDissertação de Mestradi - Instituto de Nutrição UFPE]

7. MARQUES, R. M. et al. Crescimento de crianças brasileiras; peso e altura segundo idade e sexo; influências de fatores sócio-económicos. An. Nestlé, $\mathrm{S}$. Paulo, 84 (supl. 11), 1974.

צ. MORA-PARRA, J. O. et al. La relución pesotalla en la evaluación del estado nutricional de los niños. Bogotá. Instituto Colombiano de Bienestar Familiar. 1970. [mimeografado]

9. MORA-PARRA, J. O. et al. Somatometria en niños de clase socioeconomica baja. 2. Eraluación del estado de nutrición $y$ del crecimiento em 766 pre-escolares de San Jacinto (Bolivar), Colombia. Arch. latinoamer. Nutr., 20:7-27, 1970.

10. SEOANE, N. \& LATHAN, M. C. Nutritional anthropometry in the identification of malnutrition in childhood. J. Pediat. exirron. Child Hith, 17:98-103, 1971.

Recebido para publicạão em 20/0.3/1980 Aprovado para mublicaça ent $30 / 10 / 1980$ 